\title{
Enzymes and qualitative phytochemical screening of endophytic fungi isolated from Lantana camara Linn. Leaves
}

\author{
Mbouobda Hermann Desire ${ }^{1.2^{*}}$, Fotso Bernard ${ }^{1,2}$, Muyang Rosaline Forsah ${ }^{1,3}$, Chiatoh Thaddeus Assang ${ }^{1}$, Omokolo \\ Ndoumou Denis ${ }^{2}$ \\ ${ }^{1}$ Department of Biology, Higher Teachers Training College (HTTC), The University of Bamenda, PO Box 39, Bamenda, Cameroon. ${ }^{2}$ Laboratory of Plant \\ Biology, Department of Biological Sciences, Ecole Normale Supérieure (ENS), University of Yaoundé. ${ }^{3}$ Department of Botany, Faculty of Science, \\ University of Douala; PO Box 24157 Douala, Cameroon.
}

\section{ARTICLE INFO}

Article history:

Received on: 13/09/2014

Revised on: 10/10/2014

Accepted on: $22 / 10 / 2014$

Available online: 27/12/2014

\section{Key words:}

Endophytic fungi, extracellular enzymes, secondary metabolites, plant defense.

\begin{abstract}
Plants harbor endophytes, capable of producing metabolites and enzymes with functions similar to host plant extracts. An inventory of Lantana camara's endophytes could better explain the role played by extracts of this plant in its defense functions against pathogens. This study aimed at isolating and screening endophytic fungi from $L$. camara leaves for amylases, lipases and laccases production and for the production of some secondary metabolites using standard procedures. In-vitro culture techniques with Potato Dextrose Agar (PDA) as culture medium were used to isolate endophytes from $L$. camara leaf tissues. Isolates identification were done using macroscopic and microscopic characteristics. Three endopyhtic fungi were isolated and labeled LI, LII, and LIII; LI and LII had a slimy texture and produced no reproductive structures (spores, conidia, septate hyphae etc) hence identified as mycelia sterilia. LIII was white, with an uneven surface growth, cottony dry aerial mycelium, visible hyphae with little branching and individual hyphae were septate, hence a Geotrichium sp. All isolates produced amylases and lipases while LIII solely produced laccase. The extract of LIII showed the presence of tannins and cardiac glycosides and absence of phenols and saponnins. The anti pathogenic roles of L. camara extract are thanks to the presence of endophytes in its tissues which produce enzymes that mediate plant defense functions as well as secondary metabolites with anti- pathogenic properties.
\end{abstract}

\section{INTRODUCTION}

Endophytic fungi are fungi which live in healthy plant tissues without signs of disease or morphological changes for at least part or the whole life cycle of the plant [1]. Their distribution within plant tissues is ubiquitous and varies from strain to strain as the composition of the plant tissue changes for example from root, leaf, stems fruits etc [2]. Its distribution can be affected by a range of factors such as temperature, tissues age/ nutrient composition, geography of plant etc [3]. The principal function of fungal enzymes is to hydrolyse food substances or their involvement in defense against pathogen. Lytic enzymes such as glucanase, proteinase and chitinase have been isolated from Trichoderma $s p$ and have been proven to antagonize pathogenic fungi via competition for tissues' nutrients, hence suppressing plant pathogens [4]. Laccases are important enzymes and can participate actively in establishing the pathogenicity process in plants and even directly in the degradation of lignin [5]. They are equally involved in enzymatic browning; a form of

\footnotetext{
* Corresponding Author

Email: mbouobda@yahoo.fr/mbouobda@hotmail.com

Tel (+237) 776954 88/94651869
}

plant defense [6], conversion of endogenous phenols in potential pathogenic fungi to toxic quinones, which would serve as another form of plant defense [7]. Phytochemicals (secondary metabolites) are the naturally occurring compounds present in all plant parts which together with nutrients and fibres provide protection to plants and humans against diseases. Examples include alkaloids, flavonoids, steroids, terpenoids, phenols, saponins tannins and cardiac glycosides [8], whose roles in plant defense against pathogen and stress are enormous. Anti-herbivore properties of tannins have been demonstrated by some authors $[9 ; 10]$. Some plant derived tannins such as Theaflavin, Gallic acid, Daidzein [11] are of pharmacological important. Hence, plants and endophytes with this class of metabolites are equally of great pharmacological importance. Plant Saponins act as natural insecticides to control pest insects [12], plant defense against phytopathogenic fungi [13]; with Avenacin A-1 (from young oat roots,) and $\alpha$-Tomatine (from tomato) being widely studied [14]. Phenolics are widely distributed in plants with a variety of functions; with its main function being in plant defense against pathogens and herbivore predators, and are thus applied in the control of human pathogenic infections [11]. Phenolics essentially represent a host of natural antioxidants in plants [11]. 
A wide range of phenolic substances show strong antioxidant and anti-mutagenic activities thus, can be used against cancers [8]. Glycosides are usually compounds which have been isolated in plants, made up of one or more sugars combined with an alcohol, a phenol, or a complex molecule such as a steroid nucleus.Many plants contain cardiac glycosides, which occur both in monocotyledons and in dicotyledons and have been documented as one of the chemicals in 20 well documented poisonous plants and equally possesses antimicrobial properties [15].

Plants harbor endophytic fungi capable of producing enzymes and phytochemicals on synthetic media [1]. Isolated endophytic fungi from four medicinal plants (Alpinia calcarata, Bixa orellana, Calophyllum inophyllum and Catharanthus roseus) which produced extracellular enzymes such as amylase, lipase, pectinase, protease and cellulases on potato dextrose agar (PDA) medium had been identified. Phytochemicals such as phenols, tannins, glycosides etc have equally been isolated from endophytes isolated from Centella asiatica [19].

Lantana camara Linn is a flowering ornamental plant belonging to family Verbenaceae. L. camara is widely distributed in the tropics and in the Central and Northern South America and Caribbean. It has a wide range of medicinal values ranging from cytotoxic, anti- fungal, anti-bacterial, larvicidal, to anti-oxidant, etc [16]. Enzymes and phytochemicals produced by endophytes therefore have similar roles as those from some key medicinal plants used in animal and plant protection against disease pathogen. An inventory of the endophytes of L. camara, its enzymes and metabolites is necessary as it will provide alternative sources of useful pharmaceuticals for plant and animal protection. This study is therefore aimed at screening $L$. camara for endophytic fungi and screening the endophytes for enzymes as well as for some secondary metabolites or phytochemicals which may account for the diverse role of extracts of this plant.

\section{MATERIALS AND METHODS}

\subsection{Plant material}

Leaves of L. camara were harvested along with the stem at Bambui. It is found in Tubah sub-division, Mezam division of the North West Region of Cameroon. It is located at latitude 50 99' 0 "' north and longitude $10015^{\prime} 00$ ', east. They were parceled in a plastic paper and transferred to the Biology Laboratory of HTTC, University of Bamenda. The leaves were cut off from the stem with a sterile knife (dipped in $70 \%$ alcohol) only prior to its surface sterilization 5 hours after harvest.

\subsection{Culture medium, isolation and identification of endophytic fungi}

The culture medium used was Potato Dextrose Agar (PDA); supplemented with $0.03 \%$ of freshly prepared Fortified Penicillin. The solution was sterilized by autoclaved at $115^{\circ} \mathrm{C}$ for 30 min. The sterile PDA prepared was distributed on the sterilized Petri dishes and were allowed to cool under aseptic conditions. The plant material was sterilized using standard procedures [17].
Young healthy leaves of L. camara were detached from the stem and washed with running tap water. They were transferred to $75 \%$ ethanol for 1 min followed by immersion in Sodium hypochlorite $(2.4 \%$ active chlorine) and again in $75 \%$ ethanol for $30 \mathrm{sec}$. Segments were rinsed three times with sterile distilled water, dried by pressing them in sterilized filter papers. The leaves were cut into pieces of about $1 \mathrm{~cm}^{2}$ and carefully transferred to PDA medium. All Petri dishes were sealed with parafilm and incubated at $28^{\circ} \mathrm{C}$ for 4 to 6 days, after which different strains of endophytic fungi appeared in culture medium. Their mycelia were isolated and transferred to new medium and cultured until pure fungi strains were obtained.

For the identification of endophytic fungi, pure strain were cultured in PD medium their mycelia were isolated and used to prepare slides for microscopic observations using Aniline blue solution for coloration [18]. Culture characteristics such as growth pattern, color of colony and medium, surface texture, margin characters were observed and also used for identification according to Huang et al. [22].

\subsection{Extracellular enzyme screening of pure cultures}

The pure cultures of Endophytic fungi obtained were screened for the production of extracellular enzymes activities (Amylases, Lipases and Laccasse) using qualitative techniques as described by Sunitha et al. [1]. All assays were done in triplicates.

\subsubsection{Amylase activity}

Amylase activity was assessed by growing the fungi on Glucose Yeast Extract Peptone Agar (GYP) medium (Glucose-1 g, Yeast extract $-0.1 \mathrm{~g}$, Peptone- $0.5 \mathrm{~g}$, Agar $-18 \mathrm{~g}$, distilled water-1 L) with $0.2 \mathrm{~g}$ starch. After incubation for 4 days, the plates were flooded with $1 \%$ iodine in $2 \%$ potassium iodide and white zone appearing indicated that enzyme has digested starch in medium

\subsubsection{Lipolytic Activity}

For lipase activity, the fungi were grown on Peptone Agar (PA) medium (peptone $10 \mathrm{~g}, \mathrm{NaCl} 5 \mathrm{~g}, \mathrm{CaCl} .2 \mathrm{H}_{2} \mathrm{O}-0.1 \mathrm{~g}$, agar- $18 \mathrm{~g}$, distilled water-1L) supplemented with $1 \%$ sterilized tween 20. At the end of the incubation period, a visible precipitate around the colony due to the formation of calcium salts of the lauric acid liberated by the enzyme shows a positive lipase activity.

\subsubsection{Laccase Activity}

Glucose Yeast Extract Peptone Agar medium supplemented with $0.05 \mathrm{~g} \alpha$-napthol. $\mathrm{L}^{-1}$ was used. As the fungus grew the colourless medium turned blue due to oxidation of $\alpha$ napthol by laccase.

\subsection{Phytochemical screening of secondary metabolites}

The crude extract obtained was used to screen for four metabolites as described by Heaton and Pauley [19]. All phytochemical screening assays were done in duplicates. 
2.4.1. Tannins: The crude extract was treated with alcoholic $\mathrm{FeCl}_{3}$ reagent. A bluish black colour, which disappears upon the addition of a little dilute $\mathrm{H}_{2} \mathrm{SO}_{4}$, followed by the formation of a yellowish brown precipitate indicates the presence of tannins.

2.4.2. Phenols: The extract was dissolved in $5 \mathrm{ml}$ distilled water and a few drops of $\mathrm{FeCl}_{3}$. A dark green coloration shows the presence of phenols.

2.4.3. Cardiac glycosides: The crude extract was mixed with $1 \mathrm{ml}$ of $\mathrm{FeCl}_{3}$ reagent (a mixture of 1 volume of $5 \% \mathrm{FeCl}_{3}$ solution and 99 volumes of glacial acetic acid). Add a few drops of concentrated $\mathrm{H}_{2} \mathrm{SO}_{4}$ to the solution. The appearance of greenish blue colour within a few minutes indicates the presence of cardiac glycosides.

2.4.4 Saponins: The crude extract was shaken vigorously with distilled water and allows standing for $10 \mathrm{~min}$. No froth indicates the absence of Saponins and the presence of a stable froth indicates the presence of Saponins.

\section{RESULTS}

\subsection{Isolation, purification and identification of endophytic fungi}

Three fungi strains were isolated and labeled as LI, LII, and LIII (Fig. 1). LI and LII had an even surface growth, slimy in texture and produced no reproductive structures (spores, conidia, septate hyphae etc) when observed in the light microscope at $40 \mathrm{x}$. LI was white and LII cream white. LIII was white with an uneven surface growth. Its colonies had cottony dry aerial mycelium; the undersurface of the colony developed a cream colour after about a week's growth. Microscopic observations revealed that all the three isolates produced hyphae as observed at $1000 \mathrm{x}$. LI isolate had short highly branched alternate hyphae, making the entire mycelium appearing in the form of a brush on the slides (Fig 1). LII isolate was equally highly branched, but with mycelia relatively bigger than those of LI. Isolate LIII was characterized by many visible hyphae with little branching. Individual hyphae had constrictions at the regular intervals as observed at $40 \mathrm{x}$. Mycelia of all three isolates appeared as sketched in (Fig. 1).

\subsection{Screening of isolates for enzyme activities}

All three fungi strains produced amylases, shown by the presence of clear zones at zones of fungal growth after flooding with iodine in potassium iodide and lipase activities characterized by precipitates found on the culture media at the zones of fungal growth. Only LI produces laccase characterized by blue coloration at zone of fungal growth (Fig. 2).

\subsection{Phytochemial screening of LIII extract for four secondary metabolites}

\subsubsection{Tannins}

An initial milky white solution changes into a dirty brown solution and the intensity of the brown solution increases with the addition of drops of dilute $\mathrm{H}_{2} \mathrm{SO}_{4}$ was observed in all three isolates.

3.3.2. Phenolics: In the presence of all isolates, milky white solution remains milky white upon the addition of neutral $\mathrm{FeCl}_{3}$ solution indicated the presence of phenolics.

3.3.3. Cardiac glycosides: The milky white initial solution turns light orange and finally dark green upon the addition of $\mathrm{Fe}$ $\mathrm{Cl}_{3}$ reagent and drops of Concentrated $\mathrm{H}_{2} \mathrm{SO}_{4}$ respectively.

3.3.4. Saponins: The initial wh1ite solution remains white after shaking with no froth formed. Phytochemical screening done on the extract of LIII for phenols, tannins, cardiac glycosides and saponins shows that LIII produce, cardiac glycosides and tannins but do not produce phenols and saponins (Table 1).

Table 1: Enzyme screening results of three endophytic fungi isolated from young $L$. camara leaves and cultured on specific media.

\begin{tabular}{cccc}
\hline \multirow{2}{*}{ Isolate } & \multicolumn{3}{c}{ Enzyme screening } \\
\cline { 2 - 4 } & Amylase & Lipase & Laccase \\
\hline LI & ++ & ++ & - \\
LII & ++ & ++ & - \\
LII & ++ & ++ & ++ \\
\hline
\end{tabular}

++ : presence of enzyme; -: absence of enzyme

Table 2: Chemical test results for phytochemical screening of the ethyl acetate extract of LIII, cultured on Potato Dextrose (PD) medium.

\begin{tabular}{|c|c|c|}
\hline Metabolite & Observations & Conclusion \\
\hline Saponin & $\begin{array}{l}\text { No stable froth after shaking vigorously } \\
\text { the extract with water }\end{array}$ & - \\
\hline Tannin & $\begin{array}{l}\text { dirty brown precipitate at base of test tube } \\
\text { upon addition of } \mathrm{H}_{2} \mathrm{SO}_{4}\end{array}$ & + \\
\hline Phenol & $\begin{array}{l}\text { solution remain milky white after adding } \\
\text { drops of } \mathrm{FeCl}_{3}\end{array}$ & - \\
\hline $\begin{array}{l}\text { Cardiac } \\
\text { glycoside }\end{array}$ & $\begin{array}{l}\text { dark green solution with drops of } \\
\text { concentrated } \mathrm{H}_{2} \mathrm{SO}_{4}\end{array}$ & + \\
\hline
\end{tabular}

\section{DISCUSSION}

L. camara is a source of potentially important chemical used in plant protection against pest and in medicines. Endophytic fungi distribution may account for properties of the plant extract by their ability to equally produce chemicals with properties similar to those identified in plant extracts. Endophytes were isolated from L. camara and these results were in line with those of Al-mahi et al., [2], who described endophytes as ubiquitous and found in almost all plant tissues. Two out of the three strains (LI and LII) showed one of the key characteristic of endophytic ascomycetes -low or non-sporulation which was equally isolated and identified by Nameirakpam et al., from Citrus and Zanthoxylum of Rutaceae and Cinnamomum of Lauraceae [20]. Most endophytes with these characteristics are often described as Mycelia sterile because they do not produce reproductive structures (spores) and they are widely distributed among plant hosts [21].

According to Huang et al. [22], isolate LIII, having colonies with cottony dry aerial mycelium, feathery margin in 
culture, an undersurface of the colony developing cream white colour and constrictions on the hyphae could be identified as Geotrichium sp. This major microscopic observation of constrictions on the hyphae are in line with the observations of Bourret et al. [23], who described them as zones of disarticulations of hyphae, that usually liberate cylindrical cells upon maturity called arthric conidia, key characteristic of Geotrichium sp.

All isolates produced amylases. These are in line with the results of Jayasinghe and Wettasinghe [24], where all endophytes were able to hydrolyze starch. A $100 \%$ lipase production in this research is in line with the findings of Choi et al. [25], which isolated 65 endophytic fungi from healthy leaf of Croton oblongifolius Roxb with all producing lipases. The production of these two enzymes by any potentially important endophytes showed that they use lipids and carbohydrates as energy source. Mass culturing of these endophytes will therefore require that their media should be supplemented with starch and lipids as energy source.

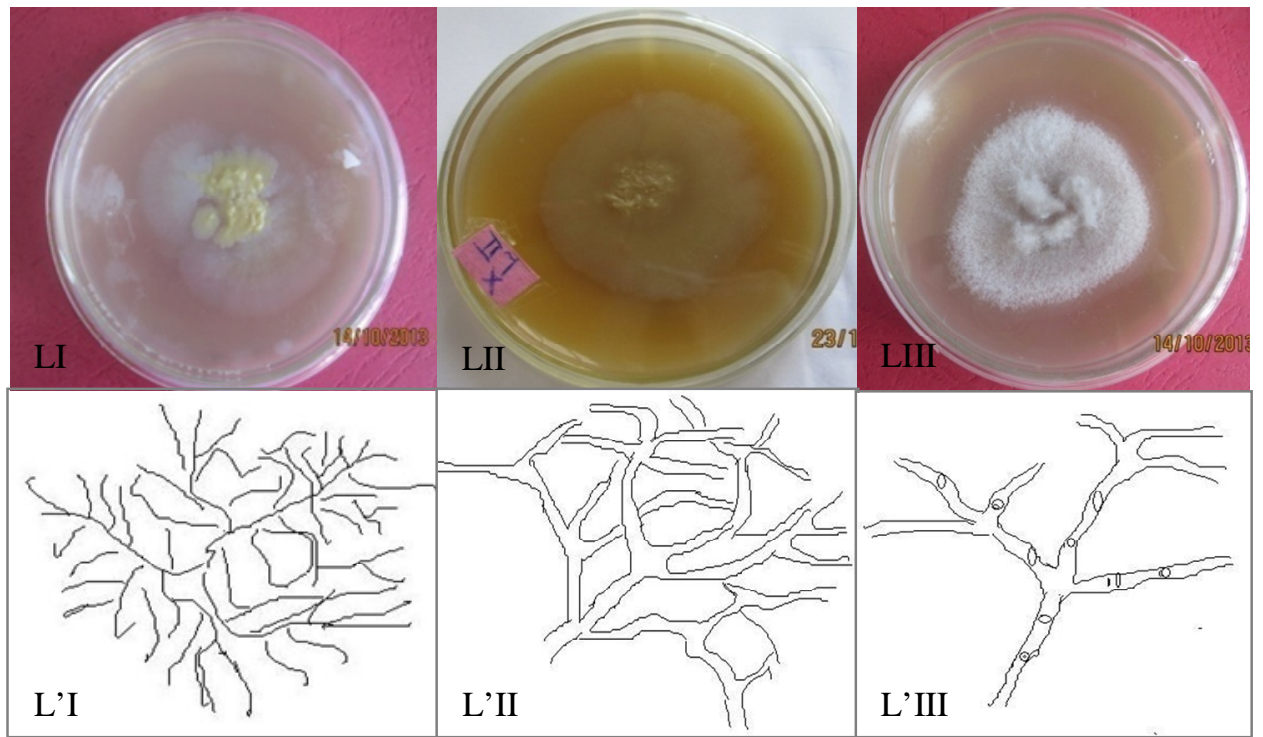

Fig. 1: Endophytes isolated from L. camara leaves (LI, LII and LIII) with their corresponding mycelia appearance on slides (L'I, L'II, L'III).
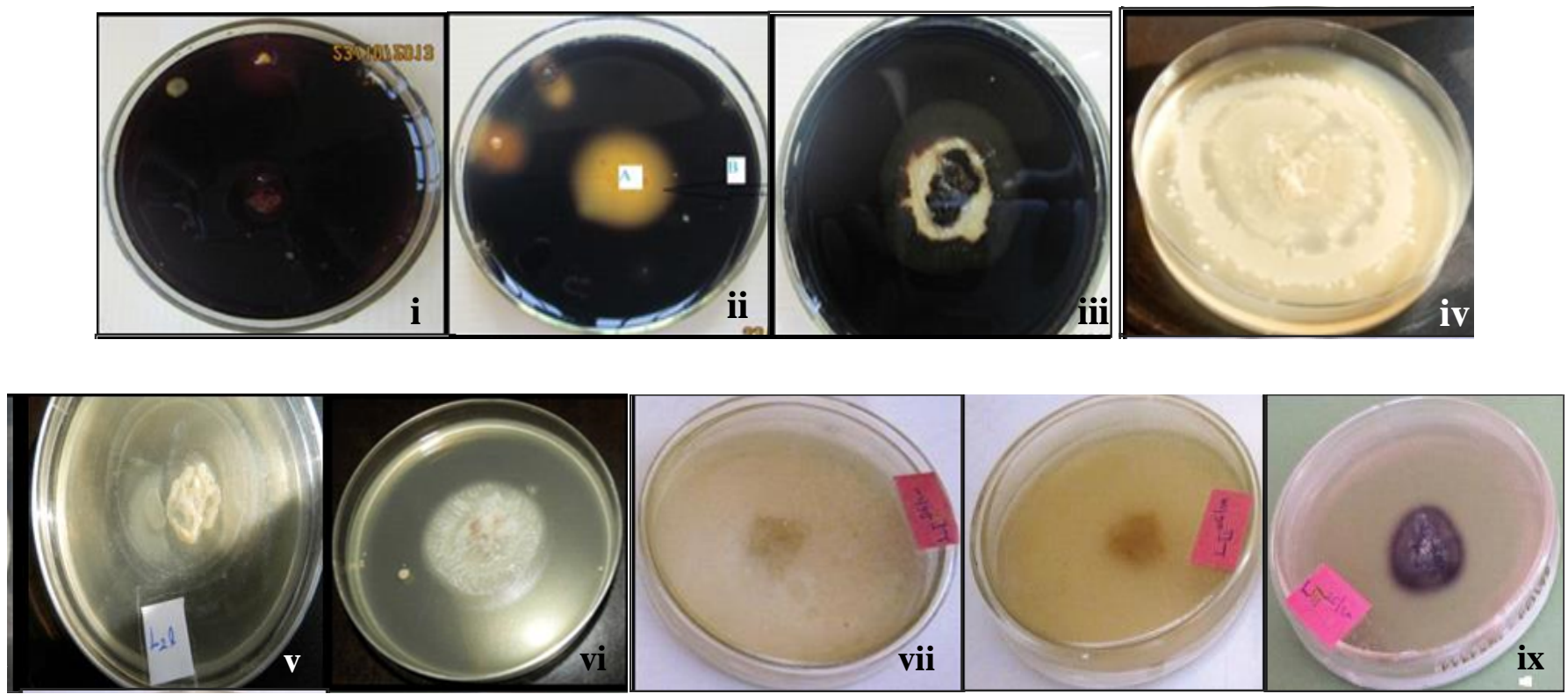

Fig. 2: Fungal screening for amylases (i-iii), lipases (iv-vi) and laccases (vii-ix) after 6 days of culture respectively in GYP supplemented with starch, PA medium supplemented with tween 20 and GYP supplemented with $\alpha$-naphthol. 
According to Saba et al. [4], the anti-fungal role of extracts may be as a result of Antagonistic competition between enzymes of the endophytes and the pathogens for tissues nutrients.

Laccase was produced only by one of the three isolated fungi. This results is in conformity with those of Sunitha et al. and Panuthai et al. [1] [26], where, among the fungal isolates obtained, only a few could produce laccase. Most laccase producers are the wood rooting fungi such as Trametes versicolor, $T$. hirsute, $T$. villosa etc, and are responsible for the removal of toxic phenols from the medium in which these fungi grew under normal conditions [27]. This property may confer the endophyte with antioxidant properties, which characterize extracts of $L$. camara. This enzyme equally finds its importance in domains such as waste detoxification, textile dye transformation, food technology, biosensors etc [28].

The screening for secondary metabolites shows that LIII produced tannins and cardiac glycosides but not saponoins and phenols. Reports showed that endophytes are sources of bioactive metabolites [19]; with tannins and cardiac glycosides being examples. The ability of an endophyte to produce some metabolites but not others has been described by Selim et al. [3]; where different endophytes in a plant may produce different secondary metabolites hence play different functions in the plant and that the total number of metabolites in a plant extract maybe a contribution of all the endophytes that live in the plant. The available secondary metabolites have anti-pathogenic properties and their roles in plant defense have been elaborated in the works of Hari et al. and Figen Mert-TŸrk [8, 15], and could be responsible for the function of the plant extracts in defense against plant and animal pathogens.

\section{CONCLUSION}

The three isolated endophytes produced two key enzymes (amylase and lipases), which are principally hydrolytic enzymes and can be explored as antagonists to some pathogenic fungi of plant and animals. Some of the anti-oxidant properties of L. camara may be thanks to the presence of laccase produced by a Geotrichium sp. These findings are also necessary to as isolated endophytes may be explored as source of phytochemicals that can be used as biocontrol agents. An inventory of the different type of phytochemicals produced by each endophyte helps in making the choice of endophyte to be amplified for the extraction of the useful metabolites. The active ingredients of $L$. camara are found on the extracts of its endophytic fungi. These endophytes as well s their enzymes will add up to the pool of potential biopesticide as well as potential sources for phamarceuticlas. Further studies on the antagonistic role of the endophytes, bioactivity of their enzymes and phytochemicals in-vitro and in-vivo are necessary.

\section{REFERENCES}

1. Sunitha V, Nirmala D, Srinivas C. Extracellular enzymatic activity of endophytic fungal strains isolated from medicinal plants. World Journal of Agricultural Sciences.2013;9(1):01-09.
2. Al-mahi I, Ietidal A and Eihab I. Antibacterial activity of endophytic fungi extracts from the medicinal plant Kigelia Africana. Egyptian Academic Journal of Biological Sciences. 2013; 5(1): 1-9.

3. Selim K, El-Beih A, Abdel-Rahman T, El-Diwany A. Biology of Endophytic Fungi. Current Research in Environmental \& Applied Mycology. 2012; 2(1): 31-82.

4. Saba H, Garima G, Shreya A, Harpreet K. Lytic Enzymes of Trichoderma: Their Role in Plant Defense. International Journal of Applied Research and Studies. 2014; 3:2-5.

5. Higuchi T. Microbial degradation of lignin, role of lignin peroxidase, manganese peroxidase, and laccase. Proceedings of Japan Academy. 2004; B80: 204-214.

6. Ferrar P, Barbere S, Ginger M, and Walker R. Laccase- new roles for an old enzyme. New Zealand Bioscience.1995; 3: 7-13.

7. Mayer A and Harel E. Polyphenol oxidases in plants. Phytochemistry.1979; 18: 193-215.

8. Hari O, Anjana S, Naseer M and Santosh K. Phytochemical screening and elemental analysis in different plant parts of Uraria picta Desv.: A Dashmul species. Journal of Chemical and Pharmaceutical Research. 2014; 6(5):756-760.

9. Phyllis D. Coley. Costs and benefits of defense by tannins in a neotropical tree. Oecologia.1986; 70:238-241.

10. Rebecca E, Robert J, and John T. Feeny revisited: condensed tannins as anti-herbivore defences in leaf-chewing herbivore communities of Quercus. Ecological Entomology.2004; 29: 174187.

11. James Hamuel Doughari. Phytochemicals: Extraction Methods, Basic Structures and Mode of Action as Potential Chemotherapeutic Agents. Department of Microbiology, School of Pure and Applied Sciences, Federal University of Technology, Yola Nigeria.

12. Publisher InTech, Published online 21, March, 2012, Published in print edition March, 2012, 33p.

13. Ellen D, Ellen L, Danny G, and Guy S. Novel Advances with Plant Saponins as Natural Insecticides to Control Pest Insects. Pest Technology. 2007; 96-105.

14. Osbourn A. Saponins and plant defence - a soap story. Trends Plant Science. 1996; 1:4-9.

15. Figen Mert-TŸrk. Saponins versus plant fungal pathogens. Journal of Cell and Molecular Biology. 2006; (13) 5:13-17.

16. Hollman A. Plants and cardiac glycosides. Br Heart. 1985; (7) 54: 258-261.

17. Sanjeeb K, Gaurav K, Loganathan K, Kokati V. and Bhaskara R. A review on medicinal properties of Lantana camara Linn. Research J. Pharm. and Tech. 2013; 5(6):711-715.

18. 17 Rezwana K, Saleem S, Iqbal C, Shakeel A and Aqeel A. Biodiversity of the endophytic fungi isolated from calotropis procera (ait.) R. BR Pak. J. Bot. 2007; 39(6): 2233-2239.

19. Heaton L.H. Pauley G.B. Two modified strains for use in oyster pathology. J. Fish Res. Board. 1969; 26: 707-709. In: Clark Geoge. Staining procedures, fourth edition (Williams and Wilkins), 1980, $512 \mathrm{p}$.

20. Nameirakpam N, Prabakaran J and Wahab F. Phytochemical analysis and enzyme analysis of endophytic fungi from Centella asiatica. Asian Pacific Journal of Tropical Biomedicine. 2012; 1280-1284.

21. Min-Yuan H, Wen-Chuan C, Hung-Chang H, Wen-Hsia C, and Wen-Hsin C. Identification of endophytic fungi of medicinal herbs of Lauraceae and Rutaceae with antimicrobial property. Taiwania. 2012; 57(3): 229-241.

22. Huang Y, Wang J, Li G, Zheng Z, and Su W. Antitumor and antifungal activities in endophytic fungi isolated from pharmaceutical plants Cephalataxus fortunei and Torreya 
grandis. Immunology and Medical Microbiology.2001; 31: 163167.

23. Bourret TB, Kramer EK, Rogers JD, Glawe DA. Isolation of Geotrichum candidum pathogenic to tomato (Solanum lycopersicum) in Washington State. North American Fungi 2013; 8 (14): $1-7$

24. Jayasinghe $\mathrm{C}$ and Wettasinghe J. Cultural characteristics and reproductive morphology of Geotrichum sp.: A guide to distinguish Geotrichum from Rigidoporus microporus. Journal of the Rubber Research Institute of Sri Lanka.1998; 81, 23-28.

25. Choi Y, Hodgkiss I. Hyde K. Enzyme production by endophytes of Brucea javanica. Journal of Agricultural Technology. 2005; 1: 55-66.

26. Panuthai T, Sihanonth P, Piapukiew J, Sooksai S, Sangvanich P. Karnchanatat, African Journal of Microbiology Research. 2012; 6 (11): 2622-2638.

27. Pragathi D, Vijaya T, MouliK C, Anitha D. Diversity of fungal endophytes and their bioactive metabolites from endemic plants of Tirumala hills- Seshachalam biosphere reserve. African Journal of Biotechnology. 2013; 12 (27): 4317-4323.
28. Madhave and Lele. Laccase properties, use. BioResources.2009; 4(4): 1694-1717.

29. Huang WY, Cai YZ, Zhang Y. Natural phenolic compounds from medicinal herbs and dietary plants: Potential use for cancer prevention. Nutr Cancer. 2010; 62 (1): 1-20

\section{How to cite this article:}

Mbouobda Hermann Desire, Fotso Bernard, Muyang Rosaline Forsah, Chiatoh Thaddeus Assang, Omokolo Ndoumou Denis. Enzymes and qualitative phytochemical screening of endophytic fungi isolated from Lantana camara Linn. Leaves. J App Biol Biotech. 2014; 2 (06): 001-006. 